\title{
Seismic imaging of the lithospheric structure of the Zagros mountain belt (Iran)
}

Anne Paul ${ }^{1, *}$, Denis Hatzfeld ${ }^{1}$, Ayoub Kaviani ${ }^{2,3}$, Mohammad Tatar $^{2}$, and Catherine Péquegnat ${ }^{1}$

(1) Laboratoire de Géophysique Interne et Tectonophysique, CNRS - Université Joseph Fourier, BP 53, 38041 Grenoble Cedex, France

(2) International Institute of Earthquake Engineering and Seismology, Tehran, Iran

(3) Institute for Advanced Studies in Basic Sciences (IASBS), P.O. Box 45195-1159, Zanjan, Iran.

* Corresponding author (e-mail: Anne.Paul@obs.ujf-grenoble.fr)

Paper to be published in "Tectonic and stratigraphic evolution of Zagros and Makran during the Meso-Cenozoic”, Geol. Soc. London. Spec. Pub., Feb. 2010.

Revised version, 3 oct. 2008

6060 words of text, 41 references, 7 figures, 1 table.

Abbreviated title: Lithospheric structure of Zagros 


\section{Abstract}

We present a synthesis and a comparison of the results of two temporary passive seismic experiments installed for a few months across Central and Northern Zagros. The receiver function analysis of teleseismic earthquake records gives a high-resolution image of the Moho beneath the seismic transects. On both cross-sections, the crust has an average thickness of $43 \pm 2 \mathrm{~km}$ beneath the Zagros fold-and-thrust belt and the Central domain. The crust is thicker beneath the hanging wall of the Main Zagros Reverse Fault (MZRF), with a larger maximum Moho depth in Central $(69 \pm 2 \mathrm{~km})$ than in Northern Zagros $(56 \pm 2 \mathrm{~km})$. The thickening affects a narrower region $(170 \mathrm{~km})$ beneath the Sanandaj-Sirjan zone of Central Zagros and a wider region $(320 \mathrm{~km})$ in Northern Zagros. We propose that this thickening is related to overthrusting of the crust of the Arabian margin by the crust of Central Iran along the MZRF considered as a major thrust fault cross-cutting the whole crust. The fault is imaged as a lowvelocity layer in the receiver function data of the Northern Zagros profile. Moreover, the crustal-scale thrust model reconciles the imaged seismic Moho with the Bouguer anomaly data measured on the Central Zagros transect. At upper mantle depth, $P$-wave tomography confirms the previously observed strong contrast between the faster velocities of the Arabian margin and the lower velocities of the Iranian micro-blocks. Our higher-resolution tomography combined with surface-wave analysis locates the suture in the shallow mantle of the Sanandaj-Sirjan zone beneath Central Zagros. The Arabian upper-mantle has shield-like shear-wave velocities, while the lower velocities of the Iranian upper mantle are likely due to higher temperature. But these velocities are not low enough and the low-velocity layer not thick enough to conclude on a delamination of the lithospheric mantle lid beneath Iran. The lack of a high-velocity anomaly in the mantle beneath Central Iran suggests that the Neotethyan oceanic lithosphere is probably detached from the Arabian margin.

(end of abstract) 
The Zagros mountain belt results from the collision of Arabia and the micro-plates of Central Iran after the closure of the Neotethyan Ocean. Although no consensus is reached on the age of the initial collision along the Zagros suture, which ranges from Late Cretaceous to Pliocene (Berberian and King, 1981; Allen et al., 2004), the Zagros has been considered as an example of a young continent-continent collision belt, for example in the pioneering thermomechanical models of continental collision by Bird et al. (1975) and Bird (1978). The rather small shortening ratios measured in the sediment cover of the Zagros fold-and-thrust belt (between 45 and $85 \mathrm{~km}, 15$ to 27\%; Blanc et al., 2003; McQuarrie, 2004; Sherkati and Letouzey, 2004; Molinaro et al., 2005a) suggest that the deep structure of Zagros is less complicated than more evolved belts like the Alps or the Himalayas. Imaging this structure should give clues on the early phases of mountain building, including the part played by oceanic slab detachment, or the role of continental subduction in the transition from oceanic subduction to continental collision. Indeed, the Zagros is located in-between the oceanic subduction of Makran and Eastern Anatolia where a number of seismic analyses suggest that the lithospheric mantle is either thinned or completely removed (Şengör et al., 2003).

As reliable data on the lithospheric structure of Iran were scarce, one of the objectives of the Iranian-French cooperative program in Earth Sciences was to investigate the deep structure of Zagros, including Moho depth variations. In that aim, we installed temporary seismic stations along two transects of Zagros for a few months each. The first one (Zagros01 in Figure 1) was located in Central Zagros, from the coast of the Persian Gulf (Busher), to the Central domain (Posht-e-Badam). The second one (Zagros03-Alborz03 in Fig. 1) crossed the whole Iranian collision zone from Northern Zagros (Khorramabad) to the Caspian Sea across the Alborz. The two transects are located on either side of the north-trending Kazerun strike-slip fault system (KF in Fig. 1) which divides the Zagros belt in two domains with different deformation styles. Structural (Tchalenko and Braud, 1974), seismotectonic (Talebian and Jackson, 2004) and geodetic (Vernant et al., 2004; Walpersdorf et al., 2006) observations show that Northwestern Zagros accommodates the oblique convergence of Arabia and Eurasia by slip partitioning between shortening within the fold-and-thrust belt, and dextral strike-slip on the Main Recent Fault, which is parallel and very close to the Main Zagros Reverse Fault (MZRF in Fig. 1). By contrast, convergence in Central Zagros is accommodated by pure shortening perpendicular to the MZRF. A comparison of the results of the two seismic experiments could give clues on possible relationships between the deformation style observed at the surface and the lithospheric structure. 
The results of the Central Zagros transect have been published in Paul et al. (2006) and Kaviani et al. (2007), while the results of the Northern Zagros transect are still unpublished. This paper focuses on the comparison of the two profiles, with special emphasis of the crustal structure.

\section{Previous data on Zagros lithospheric structure}

Crustal structure studies published prior to our seismic transects mainly deal with gravity data. Dehghani and Makris (1984) produced a Bouguer anomaly map of Iran from a dense set of stations and computed a crustal thickness map from the gravity variations. The main feature of the Bouguer anomaly map is a strong negative anomaly trending northwestsoutheast centred on the MZRF. Its absolute minimum of -230 mgal is located between Shiraz and Esfahan. According to Dehghani and Makris (1984), this negative gravity anomaly gives a maximum crustal thickness of 50 to $55 \mathrm{~km}$ located right beneath the MZRF, and a normal thickness of $\sim 40 \mathrm{~km}$ beneath the Persian Gulf coast and Central Iran. The more detailed Bouguer anomaly modelling of Snyder and Barazangi (1986) is focused on the Zagros region. They find a maximum crustal thickness of 55 to $60 \mathrm{~km}$ beneath the MZRF, but they argue that the Zagros topographic load is insufficient to explain the observations in terms of simple lithospheric flexure.

All published controlled-source seismic profiles recorded in the Zagros for oil exploration purposes are limited to the sediments above the thick Hormuz salt layer which acts as a barrier for seismic waves. Giese et al. (1984) report on refraction profiles recorded from quarry blast sources in southeastern Zagros, but their conclusions are not supported by reverse profiles and the data quality is poor. Hatzfeld et al. (2003) used receiver function analysis from earthquake records to infer a crustal thickness of $\sim 46 \mathrm{~km}$ beneath a single station in Central Zagros.

Most results published on the structure of the lithospheric mantle come from seismology. The only exception is the combined modelling of topography, Bouguer anomaly, and geoid data by Molinaro et al. (2005b) who suggest that the lithospheric mantle could be much thinner beneath Zagros and the Iranian margin than beneath the Persian Gulf. From a regional analysis of surface wave records, Maggi and Priestley (2005) show that the upper mantle (at 100-150 km depth) of the Turkish-Iranian plateau has lower $S$-wave velocities than surrounding regions like the Persian Gulf, Northern Arabia or the Southern Caspian. They argue on the spatial correlation of this low-velocity anomaly with a positive long-wavelength 
free-air gravity anomaly indicative of a less dense mantle, and with recent volcanism with lower mantle signature, to propose a possible delamination of the lithospheric mantle beneath Central Iran. The resolution of their tomography is too low (a few hundreds km) to delineate the low-velocity anomaly and relate it to geological features like the MZRF. This upper mantle low-velocity anomaly has been confirmed for both $P$ and $S$ waves in a recent inversion of body wave arrival times by Alinaghi et al. (2007). Hearn and Ni (1994) and Al-Lazki et al. (2004) studied the $P n$ phase, the conic $P$ wave that propagates in the shallowest upper mantle for regional earthquake-station distances. They show that $P$-wave velocities are higher (8.1$\left.8.4 \mathrm{~km} . \mathrm{s}^{-1}\right)$ beneath the Zagros than beneath most of the Iranian plateau $\left(7.9-8.1 \mathrm{~km} . \mathrm{s}^{-1}\right)$. The boundary between lower and higher velocities coincides roughly with the MZRF. Al-Lazki et al. (2004) interpret this observation as an indication for absent or limited underthrusting of the higher-velocity upper mantle of Arabia beneath the lower-velocity upper mantle of Central Iran.

Alinaghi et al. (2007) show depth cross-sections of their velocity models to address the question of the Neotethyan slab break-off. Their images show northward-dipping highvelocity anomalies in the mantle beneath the low-velocity anomaly of Central Iran, which can be interpreted as remnants of the oceanic lithosphere. However, the cross-sections are quite complex, some of them showing a clear continuity of the high-velocity anomaly from shallow (Arabian platform) to large mantle depths, while the anomaly is discontinuous in other crosssections located a few tens of $\mathrm{km}$ apart.

\section{Data acquisition and processing}

Figure 1 shows a location map of temporary seismic stations installed by French-Iranian teams across the Zagros. The 67 stations of the Central Zagros experiment, named Zagros01, were operated along a 620-km transect from November 2000 to April 2001. From southwest to northeast, it crosses the Zagros fold-and-thrust belt (ZFTB), the Sanandaj-Sirjan metamorphic zone (SSZ), the Urumieh-Dokhtar magmatic assemblage (UDMA) and reaches the southern tip of the Central domain (CD). Regarding the logistics, this location was the easiest transect across the most two-dimensional part of the range. However, the southeasternmost part of the profile follows the Kazerun fault which is now considered as part of an orogen-scale fault system along which dextral slip on the Main Recent Fault is transferred (Authemayou et al., 2006). This major tectonic structure probably has a structural signature which could make the Zagros01 transect less representative of the two-dimensional Central 
Zagros belt. The second experiment, named Zagros03, crossed Northern Zagros and the plateau from May to November 2003 (42 stations, $470 \mathrm{~km}$ ). It was complemented in Central Alborz by a 2-D array of 25 stations from the Seis-UK and Cambridge University pools operated in the same time period (array name: Alborz03). Both transects were mostly equipped with sensors with natural period above $5 \mathrm{~s}$, including small sub-networks of broadband sensors suitable for surface-wave studies (natural periods 90s and 120s).

The results summarized in this paper were obtained from records of teleseismic earthquakes with magnitude larger than 5.5. The number of events used ( 100 for each experiment) is large enough for a fair resolution in spite of a limited azimuthal coverage (most events with back-azimuths in the range $20-110^{\circ}$ ).

Mapping Moho depth is one of the major goals of this type of experiment. This information is obtained by receiver function analysis, an efficient tool to image sharp velocity and density discontinuities at depth beneath seismic stations (Vinnik 1977, Langston 1979). Receiver function (RF) analysis is based on a deconvolution of the first few seconds of signal after the arrival of the $P$ wave in the radial component of teleseismic records. It aims at measuring the time delay between the primary $P$ and the $P S$ phase which is a $P$ wave converted to $S$ at velocity discontinuities beneath the station. The $P s-P$ time difference depends on the depth to the discontinuity, the $P$-wave velocity $(V p)$ model and $V p / V s$ ratio between the discontinuity and the surface. Thus reasonable assumptions on the values of $V p$ and $V p / V s$ lead to depth estimates from $P S-P$ delay time measurements. We computed receiver functions using the time domain iterative deconvolution method of Ligorria and Ammon (1999), and migrated depth sections using the common conversion point (CCP) method of Zhu and Kanamori (2000).

The tomography of the upper mantle was achieved by inversion of teleseismic traveltime residuals for lateral variations of $P$-wave velocity beneath the seismic array. $P$-wave arrival times are picked at each station for earthquakes at teleseismic distance. Then, traveltime residuals are computed by subtracting theoretical traveltimes computed in a standard spherical Earth model from observed traveltimes, and the average residual for each event is subtracted from the relevant absolute residuals to give relative residuals. The relative residuals are sensitive to lateral velocity variations beneath the array. Then, the set of residuals is inverted for a three-dimensional model of $P$-wave velocity relative variations $(\Delta V p / V p)$ beneath the array. We used the "tomo3d" implementation (Judenherc, 2000) of the widely-used and robust ACH inversion method of teleseismic residuals by Aki et al. (1977) improved by the "shift-and-average" procedure of Evans \& Achauer (1993) to attenuate the influence of the 
horizontal sampling in discrete blocks. One of the drawbacks of $\mathrm{ACH}$ is that it does not give absolute velocity. Therefore, we also estimated horizontally-averaged absolute $S$-wave velocity depth models from the inversion of surface-wave dispersion curves for the Zagros01 experiment (Kaviani et al., 2007). As absolute $S$-wave velocities can be interpreted in terms of compositional or thermal changes with depth, they are a good complement to $\mathrm{ACH}$ tomography which detects lateral velocity variations with a fair horizontal resolution of a few station spacings $(\sim 30 \mathrm{~km})$.

\section{Crustal thickness variations from receiver function analysis}

Figures 2 and 3 show receiver function depth cross-sections for the 2 transects. They were computed by projection of the receiver function data on the average profiles shown as dashand-dot lines in Fig. 1. Figures $2 \mathrm{~b}$ and $3 \mathrm{~b}$ result from a CCP time-to-depth migration assuming the crustal velocity models of Table 1, which takes the 11-km thick sediment layer of the ZFTB into account for stations located southwest of the MZRF according to the model computed by Hatzfeld et al. (2003). For stations northeast of the MZRF where no information is available, we assumed a 2-layer model. The $V p / V_{s}$ ratio is a critical parameter in the timeto-depth migration of receiver functions, which can be estimated using the multiples of the Moho conversion (e.g. Zhu and Kanamori, 2000). Due to a poor signal-to-noise ratio, we could not use the multiples in the Zagros01 profile, and we assumed the values given by Hatzfeld et al. (2003). The multiples are clearer on the better-quality records of the Zagros03 transect, and we found 1.8 for the crustal average $V p / V s$, without significant variations along the profile. We used this value for the Zagros03 and Alborz03 transects (Table 1). The effect of using different $V p / V s$ ratios in the migrations of the 2 Zagros profiles will be discussed later.

Figures $2 \mathrm{c}$ and $3 \mathrm{c}$ display stacked radial $\mathrm{RF}$ with the time axis converted to a depth axis using the same crustal velocity models as above. We stacked all RF with a common conversion point at the Moho ( $\pm 5 \mathrm{~km}$ measured along the average profile), and plotted them at the abscissa of the conversion point. An average of 14 radial RF have been stacked to obtain the 62 traces plotted in Fig. 2c, and 29 of these 62 traces (47\%) result from the stack of less than 10 receiver functions. Due to the longer duration of the experiment and better-quality records, the cross-sections of Figure 3 have a better resolution than in Figure 2, with an average of 37 stacked RF, and only 9 of the 66 traces (14\%) resulting from the stack of less than 10 RF. The 2 plots (migrated depth section and section of stacked RF) are different displays of the same 
information. While the section of stacked RF shows waveforms with little processing, the CCP migrated section is smoother, making it easier to pick interfaces. Wavelets of positive amplitude (filled in red) are generated by a velocity increase with depth while wavelets of negative amplitude (filled in blue) correspond to a velocity decrease. The laterally continuous positive wavelet at $\sim 50 \mathrm{~km}$ depth outlined with a thick black line is the conversion on the Moho. We estimate to $\pm 2 \mathrm{~km}$ the uncertainty on the picks of the Moho from the migrated RF depth sections. The uncertainty on absolute depths is larger as we have no precise estimate of the crustal $V p$ and $V p / V s$ models. For example, changing the $V p / V s$ model of the Zagros01 transect to a constant value of 1.8 (as for the Zagros03 transect) reduces the estimated Moho depth by 3 to $6 \mathrm{~km}$.

Assuming a constant $V p / V s$ ratio of 1.8 , we find an average crustal thickness of $42 \pm 2 \mathrm{~km}$ beneath the Zagros fold belt and the Central Domain (CD in Figs. 2 and 3) on both transects. In Central Zagros (Fig. 2), the Moho depth increases strongly from $30 \mathrm{~km}$ southwest of the MZRF to $140 \mathrm{~km}$ northeast of it. The maximum depth reached is $69 \pm 2 \mathrm{~km}$ (or $63 \pm 2 \mathrm{~km}$ assuming $V p / V s=1.8$ ) between 50 and $90 \mathrm{~km}$ northeast of the surface trace of the MZRF. No such spectacular bend is visible on the Moho depth profile of the northwestern transect (Figure 3), where the crust is thickened on a broader length $(\sim 320 \mathrm{~km}$ between abscissas -50 and $270 \mathrm{~km}$, instead of $170 \mathrm{~km}$ - between abscissas -30 and $140 \mathrm{~km}$ - in Zagros01) and the maximum depth reached $(56 \pm 2 \mathrm{~km}$ at $\mathrm{km} \mathrm{130)}$ is smaller. The reliability of the very large crustal thickness found beneath the SSZ on the Zagros01 transect is thoroughly discussed in Paul et al. (2006). Explaining the 20-to-25-km difference in Moho depth by an artificial pull down in the migrated depth section would require an average crustal $P$-wave velocity of 5.2 $\mathrm{kms}^{-1}$ combined with a $V p / V s$ ratio of 2.0 for the crust of the SSZ, which is unreliable.

Figure 4 shows a comparison of elevation (Fig. 4a), Bouguer anomaly (Fig. 4b) and picked Moho depth profiles (Fig. 4c) along the two transects. The Moho depth profile of the Zagros01 transect has been corrected to a constant $V p / V s$ of 1.8 to enable the comparison with the Zagros03 data. The distance scale of the Northern profile is multiplied by 0.94 to correct for the difference in the width of the SSZ between the two transects. Even after this scale reduction, Fig. $4 \mathrm{c}$ shows that the region of thickened crust is much wider beneath Northern than beneath Central Zagros, but the maximum thickness is smaller. In both cross-sections, crustal thickening starts beneath the north-easternmost part of the ZFTB. The zone of thick crust covers the MZRF region and the SSZ in Zagros01 transect, while it also includes the UDMA and the southern part of the CD in Zagros03. The maximum crustal thickness is shifted toward the northwest in Zagros03 with respect to Zagros01. The location of the 
maximum Moho depth does not coincide with the minimum Bouguer anomaly which is located in both profiles at the surface outcrop of the MZRF (Fig. 4b). To reconcile the gravity data with the Moho depth profile, Paul et al. (2006, Figure 6b) proposed that the crust of Central Iran overthrusts the crust of Zagros on the MZRF interpreted as a crustal-scale structure rooted at Moho depth (dashed line in Figures $2 b$ and $2 c$ ). This model explains at least part of the crustal thickening by the superposition of the two crusts. The almost double thickness of the dense lower crust beneath the SSZ compensates for the negative gravity anomaly induced by the thick crust and shifts the Bouguer anomaly minimum toward the southeast, in agreement with observations. Only the few RF recorded at stations in the southwestern half of the SSZ display a negative wavelet at depths close to the trace of the MZRF in the model tested by gravity modelling (Fig. 2c). There is no evidence for a major thrust rooted at Moho depth beneath the northeastern half of the SSZ. But this might be due to a much lower station coverage and poor data quality. Only 2 stacked traces could be shown in Fig. 2c between offsets 65 and $105 \mathrm{~km}$, and they were computed from only 1 (at offset $65 \mathrm{~km}$ ) and 2 (at offset $85 \mathrm{~km}$ ) individual RF. The much better-quality sections of Zagros03 (Figure 3) display a strong amplitude converted phase with negative polarity and north-eastward dip, crossing the crust from the surface trace of the MZRF to Moho depth at km 250-270. Figure $3 \mathrm{c}$ shows that the wavelet of negative polarity (blue-filled) is followed by a positive wavelet of smaller-amplitude (red-filled) in all stacked RF between abscissas 20 and $110 \mathrm{~km}$. Waveform modelling shows that these signals can be generated by a low-velocity layer possibly related to the underthrusting of the sediments of the Arabian margin dragged to depth by the subduction of the Neotethyan Ocean (Paul et al., 2008).

\section{Lateral variations of seismic wave velocity in the lithosphere}

While receiver functions image sharp velocity discontinuities like the Moho, lateral velocity variations are estimated from traveltime studies. Figure 5b (redrawn from Kaviani et al., 2007) shows the teleseismic $P$-wave traveltime relative residuals measured at stations of Zagros01. Residuals are plotted at the abscissa of the projection of the relevant station onto the average profile. Residuals were measured from traveltime picks of $P$ waves on records of 111 earthquakes at teleseismic distance $\left(25-95^{\circ}\right)$. The residual curve displays both longwavelength variations, with earlier arrivals (negative residuals) at stations in the southwest than in the northeast (positive residuals), and short-wavelength variations, with later arrivals in the MZRF region and earlier arrivals in the SSZ. The residuals were back-projected by the 
ACH inversion method to a 3-D model of $P$-wave velocity perturbation which explains 85 per cent of the initial data variance. Figure $5 \mathrm{c}$ shows a depth cross-section in the 3-D model along the average profile. Relative velocity variations are displayed only where the resolution is fair (diagonal term of the resolution matrix larger than 0.6 for the crustal layer and 0.7 for the mantle layers). The $\sim 0.9 \mathrm{~s}$ traveltime difference observed between the two ends of the profile projects to a strong velocity contrast in the upper mantle down to $200 \mathrm{~km}$ depth, with faster velocities beneath the Zagros and slower velocities beneath the UDMA and CD. Figure 5c also shows 2 average $S$-wave velocity depth models of the upper mantle estimated by Kaviani et al. (2007) from surface-wave dispersion measurements. They were measured in two subarrays of the Central Zagros transect which cover the ZFTB (sub-array AB) and the MZRFSSZ-UDMA areas (sub-array BCD) respectively. $S$-wave velocities are rather high beneath the Zagros (4.5 to $4.9 \mathrm{~km} . \mathrm{s}^{-1}$ ), and they increase regularly with depth. This is not the case beneath the MZRF-SSZ-UDMA region where a low-velocity zone $\left(4.4 \mathrm{~km} . \mathrm{s}^{-1}\right.$ minimum velocity) is detected in the shallow mantle from the Moho to $150 \mathrm{~km}$ depth. Therefore, we have two independent arguments to conclude on a strong velocity contrast in the lithospheric mantle beneath the Central Zagros transect. This observation agrees with the results of the regional tomography studies by Maggi \& Priestley (2005) and Alinaghi et al. (2007) which show that the upper mantle beneath the Iranian plateau has low $P$ - and $S$-wave velocities. However, our study conducted from a local dense station array shows that the suture between the faster-velocity Arabian upper mantle beneath the ZFTB and the lower-velocity Iranian upper mantle is located beneath the MZRF or the SSZ regions. But Figure 5c shows that the precise location and shape of the suture are hidden by smearing of shallow velocity anomalies.

The late arrivals observed at stations in the MZRF region project to a low-velocity anomaly concentrated at shallow depth $(<100 \mathrm{~km})$. As discussed by Kaviani et al. (2007), this lowvelocity anomaly could be explained by crustal thickening. But the high-velocity anomaly beneath the northeastern part of the SSZ in the same 2 upper layers is surprising as the crust is also thickened there. To explain this paradox, Kaviani et al. (2007) show that the model of crustal-scale thrust proposed by Paul et al. (2006) gives an acceptable fit to traveltime and surface wave observations if it is combined with an extension of the Zagros mantle highvelocity anomaly beneath the SSZ.

Figure 6 displays the relative residual variations and $P$-wave tomogram along the average profile of the Zagros03 and Alborz03 arrays. Arrival times of 138 teleseismic earthquakes have been used in this inversion which explains 83 per cent of the initial data variance. As for 
Zagros01, the earliest $P$ arrivals are observed at the southwestern end of the profile. The latest arrivals are picked at stations of the northeastern part of the SSZ and in the UDMA, and at stations on top of the southern flank of the Alborz. The contrast between the high-velocity upper mantle of the Arabian plate and the lower-velocity upper mantle of Central Iran explains the $\sim 1.2 \mathrm{~s}$ residual difference between the southwestern end of the profile and stations in the CD. Again, the location of the suture in the $50-100 \mathrm{~km}$ layer is blurred by a lowvelocity anomaly. Unlike the Central Zagros transect, this anomaly is spatially correlated with the region of thick crust, and the thickening explains at least half of the 0.3 to $0.5 \mathrm{~s}$ difference between the residuals observed in the UDMA and in the CD. No strong crustal low-velocity anomaly is required to explain the traveltime observations in the UDMA, in contrast with the strong low- and high-velocity anomalies required in the crust beneath the MZRF and SSZ in the Zagros01 transect (Kaviani et al., 2007).

\section{Discussion and Conclusions}

\section{Crustal-scale thrust}

The Zagros01 and Zagros03 passive seismic experiments have provided images of the lithospheric structure of the Zagros mountain belt with unprecedented resolution. Assuming reasonable crustal $V p$ models and a constant crustal $V p / V s$ ratio of 1.8, the receiver function analysis shows that the average crustal thickness beneath the ZFTB is the same for the two transects: $42 \pm 2 \mathrm{~km}$. Thus, we could conclude as Hatzfeld et al. (2003) that the crystalline crust of the ZFTB has not been significantly thickened by the collision yet, in Central Zagros and in Northern Zagros. Indeed, the crystalline crust has about the same thickness $(33-35 \mathrm{~km}$, with $10 \mathrm{~km}$ of sediments) as the pre-collisional Arabian platform. However, the lack of precise information on the actual average crustal $P$-wave velocity and $V p / V s$ ratio leads to an uncertainty as large as $5 \mathrm{~km}$ on the absolute Moho depth estimate, which prevents from drawing definite conclusions. Mouthereau et al. (2006) concluded from critical wedge modelling that basement-involved thickening and shortening of the Arabian crust is required to support the growth of topography in the ZFTB. As the induced crustal thickening beneath the ZFTB is smaller than a few $\mathrm{km}$, their model is compatible with our observations.

There is no clear evidence for the existence of a major thrust fault cross-cutting the whole crust in the Zagros01 receiver function depth section. But the station coverage in the SSZ was weaker and the seismic records of lesser quality than in the Zagros03 transect. The model of crustal-scale overthrusting of the Iranian margin on the Arabian margin along the MZRF was 
proposed by Paul et al. (2006) to reconcile the Moho depth profile with Bouguer anomaly data. But the better-quality data of the denser Northern Zagros experiment clearly display an intra-crustal interface with negative polarity (velocity decreasing with increasing depth), followed closely by an interface of positive polarity. The negative-polarity signal crosses the entire crust from the surface exposure of the MZRF to Moho depth beneath the southern rim of the CD. These evidences for a low-velocity layer confirms that the MZRF is a major crustal-scale thrust, at the suture between the Arabian platform and the micro-blocks of Central Iran. This interpretation also relies on geological arguments. Firstly, there are strong evidences that the SSZ overlaps the highly deformed rocks of the so-called Crush zone of the MZRF region (e.g. Stöcklin 1968; Ricou et al. 1977). Secondly, Agard et al. (2005) rely on the amount of shortening, the deformation style and the lack of high-pressure metamorphism along the former oceanic suture in the Crush zone to suggest that the MZRF is a major structure of crustal scale, possibly rooted to Moho depth.

As documented by Figure 4c, crustal thickening involves the SSZ in Central Zagros, and the SSZ, the UDMA and part of the CD in Northern Zagros. The RF migrated section of Zagros03 shows that the MZRF interpreted as a crustal-scale thrust roots at Moho depth (43 $\mathrm{km}$ ) $270 \mathrm{~km}$ to the northeast of its surface exposure, with an average dip of $9^{\circ}$ (Fig. 3). If the geometry proposed for Central Zagros by Paul et al. (2006) is correct, the MZRF roots at Moho depth only $170 \mathrm{~km}$ northeast of its surface trace, with a stronger average dip of $14^{\circ}$.

On the basis of tectono-sedimentary evidences, basin analysis, crustal wedge modelling and seismotectonic observations, Mouthereau et al. (2007) propose a new crustal-scale balanced cross-section of Central Zagros where a large part of the shortening is accommodated by underplating of Arabian crustal duplexes beneath the MZRF (Figure 7b). Their model implies that crustal thickening beneath the SSZ is related to the inversion of the Arabian margin after the onset of plate coupling along the former subduction zone (Fig. 7a). This hypothesis qualitatively agrees with our crustal depth profiles as we show that crustal thickening is located right under the trace of the MRZF cross-cutting the whole crust. For a more quantitative testing, we computed the surfaces of the crustal roots of Central and Northern Zagros (depth $\geq 42 \mathrm{~km}$; grey-filled area in Figure $7 \mathrm{~b}$ ) from the two Moho depth profiles of Figures 2 and 3, and we converted these surfaces to crustal shortening estimates assuming inplane deformation. We find a finite shortening of $59 \mathrm{~km}(23 \%)$ for Central Zagros, and $49 \mathrm{~km}$ (13\%) for Northern Zagros. These numbers agree with the model proposed by Mouthereau et al. (2007) where $75 \%$ of the total shortening, that is $49-58 \mathrm{~km}$, is taken up by underplating of the Arabian basement beneath the SSZ. 
As explained in the introduction, we installed two seismic profiles because we expected that the difference in the active deformation process between Northern and Central Zagros would have an expression, or an origin, in the lithospheric structure. We do find that the crustal root has different widths and amplitudes, in relation with the lateral change of the MZRF dip. The surface of the crustal root is $20 \%$ larger in Central Zagros than in Northern Zagros, leading to the observed $10 \%$ difference in the shortening ratios. We find a stronger shortening in Central Zagros, as expected from its farther location to the Euler rotation pole between Arabia and Central Iran (Vernant et al., 2004). However, since error bars on our Moho depth estimates are large $( \pm 5 \mathrm{~km})$ due to poor constraints on the $V p$ and $V p / V s$ crustal models, this positive correlation cannot be taken as granted. Teleseismic traveltime tomography also documents along-range variations of crustal $P$-wave velocity anomalies. A significant part of the shortwavelength lateral variations of relative residuals measured along Zagros03 transect can be explained by thickness variations of a crust with limited lateral velocity changes. This is not the case in Zagros01 transect where a low average crustal velocity beneath the MZRF and a high average crustal velocity beneath the SSZ are required to explain the traveltime observations. Kaviani et al. (2007) proposed to explain the low-velocity anomaly of the MZRF region by crustal thickening combined with thickening of the sedimentary wedge in front of the thrust, and the high-velocity of the SSZ by superposition of the two lower crusts by the crustal-scale thrust, combined with upper mantle high velocities. The smaller lateral velocity changes in the crust of Northern Zagros suggest that crustal structure changes more smoothly, which is coherent with the larger width of the region affected by crustal-scale thrusting in relation to the smaller dip of the MZRF.

\section{Lateral velocity contrast in the upper mantle}

The traveltime study, combined for Zagros01 with surface-wave dispersion analysis, confirms that seismic velocities in the shallow mantle $(50-200 \mathrm{~km})$ are faster in the margin of Arabian platform than in the Iranian micro-blocks. This contrast has already been documented at the regional scale of the Turkish-Iranian plateau from less well-resolved tomographies, and both for $P$ - and $S$-wave velocities (Maggi and Priestley, 2005; Alinaghi et al., 2007). Our study provides more precise indications on the location of the suture between the two upper mantle lids, and on the velocity contrast. Considering that the laterally heterogeneous upper mantle layer is $150-\mathrm{km}$ thick, as documented by the Rayleigh-wave dispersion inversion (Fig. 5d), a lateral $\mathrm{Vp}$ contrast of 5 to 7 per cent is required to explain the 0.9 to $1.2 \mathrm{~s}$ difference observed 
in the traveltime curves of the 2 transects. Kaviani et al. (2007) used independent arguments from $P$-wave tomography and surface-wave analysis to propose that the high-velocity upper mantle of Arabia extends toward the northeast beneath the SSZ in Central Zagros. However, strong crustal velocity anomalies in the MZRF and SSZ areas leak to mantle depth and hide the exact location and shape of the suture in the Zagros01 profile (Fig. 5c). In the Zagros03 profile, the location of the suture between high and low velocities in the 50-100 km layer is blurred by the low-velocity anomaly associated with crustal thickening. At larger depth, Figure 6c documents a smooth transition located beneath the Central Domain (CD) at abscissa $\sim 250 \mathrm{~km}$, that is close to the abscissa where the crustal-scale thrust imaged by receiver functions reaches the Moho. Thus, our data show that the fast-velocity lithospheric mantle of Arabia extends to $\sim 140 \mathrm{~km}$ northeast of the surface exposure of the MZRF in Central Zagros and $\sim 250 \mathrm{~km}$ in Northern Zagros, in agreement with the proposed model of crustal-scale underthrusting of the crust of Arabia by the crust of Central Iran.

Kaviani et al. (2007) discussed the inferences on the geodynamics that can be made from the tomographic images of the Zagros01 transect. The shear-wave absolute velocity depth models estimated from Rayleigh wave dispersion analysis (Fig. 5d) can be interpreted in terms of compositional and thermal constraints, which is not the case for the relative $P$-wave velocity tomograms. The high $S$-wave velocities measured in the upper mantle of the Zagros are comparable to those of a shield. The difference $\left(0.5 \mathrm{~km} . \mathrm{s}^{-1}\right)$ between the two $V_{s}$ models measured in the Zagros and in the MZRF-SSZ-UDMA region (Fig. 5d) in the shallow mantle is likely due to a compositional change (hydrated minerals for example) related to higher temperatures beneath the MZRF-SSZ-UDMA. However, Kaviani et al. (2007) believe that the $V S$ constrast is too weak to support the hypothesis of lithospheric mantle delamination proposed by Maggi and Priestley (2005).

Kaviani et al. (2007) explain that the $V p$ tomogram of Figure 5c gives no definite answer on the question of oceanic slab breakoff. The image of the Neotethyan lithosphere still attached to the Arabian margin would be impossible to separate from the effect of crustal and upper mantle heterogeneity in the suture region. The $V p$ tomogram of Zagros03 (Fig. 6c) is less blurred by crustal structures in the upper mantle northeast of the suture. In the upper 2 layers (0-100 km), there is no high velocity anomaly like the one observed beneath the SSZ in the Zagros01 profile. And the upper mantle high-velocity anomaly that would be associated with the oceanic lithosphere attached to the Arabian margin does not appear more at larger depths in Figure 6c. That is why we believe that the slab could be detached from the Zagros margin. Kaviani et al. (2007) give additional elements favouring this hypothesis including the lack of 
Ps conversion in the receiver function sections under the Moho beneath the UDMA and CD. Hafkenscheid et al. (2006) also concluded on the occurrence of slab detachment beneath the Zagros suture zone from a comparison of tectonic reconstructions and the mantle tomography of Bijwaard et al. (1998). The recent discovery in the Central part of the UDMA of adakitic magmas representing potential markers of the melting at depth of oceanic crust suggests slab break-off or slab tear propagation from Eastern Anatolia to Central Iran in the last c. 10-5 Ma (Omrani et al., in press).

Our model of the structure of the Zagros lithosphere at the onset of continental collision and at present time is schematized in Figure 7. The crust of the Iranian microcontinent overthrusts the crust and mantle of the Arabian margin until the 2 plates are strongly coupled. The ongoing convergence induces crustal thickening beneath the SSZ by underplating of Arabian crustal duplexes and folding and thrusting in the ZFTB. At mantle depth, the Neotethyan slab detaches from the Arabian margin; a new Moho is created (by thermal relaxation and eclogitization) beneath the MZRF crustal-scale thrust; the mantle of the Iranian lithosphere is heated by upwelling induced by slab breakoff; its shallow part $(50-150 \mathrm{~km})$ keeps higher temperature and lower seismic velocities than the neighbouring fast-velocity mantle of the Arabian platform.

Acknowledgments: The Zagros01, Zagros03 and Alborz03 experiments were funded by IIEES (International Institute of Earthquake Engineering and Seismology, Iran), and INSU-CNRS (France). Instruments belong to the French national pool of mobile seismic instruments Sismob with complement from the British national pool Seis-UK for Alborz03 in collaboration with K. Priestley (University of Cambridge). We thank the President of IIEES, Prof. Ashtiany, and the Director of the Seismology Department, Dr Mokhtari, for their constant support. AK and MT received fellowships from the French Embassy in Iran for their Ph-D studies in France. Many people participated in the field experiments. They are warmly acknowledged. 


\section{References}

Agard, P., J. Omrani, L. Jolivet, and F. Mouthereau, 2005. Convergence history across Zagros (Iran): constraints from collisional and earlier deformation, International Journal of Earth Sciences, doi 10.1007/s00531-005-0481-4.

Aki, K., A. Christoffersson, and E.S. Husebye, 1977. Determination of 3-dimensional seismic structure of the lithosphere, J. Geophys. Res., 82(2), 277-296.

Alinaghi, A., I. Koulakov, and H. Thybo, 2007. Seismic tomographic imaging of $P$ - and $S$ waves velocity perturbations in the upper mantle beneath Iran, Geophys. J. Int. 169 (3), 1089-1102. doi:10.1111/j.1365-246X.2007.03317.x.

Al-Lazki, A.I., E. Sandvol, D. Seber, M. Barazangi, N. Türkelli, and R. Mohamad, 2004. Pn tomographic imaging of mantle lid velocity and anisotropy at the junction of the Arabian, Eurasian and African plates, Geophys. J. Int., 158, 1024-1040.

Allen, M., J. Jackson, and R. Walker, 2004. Late Cenozoic reorganization of the ArabiaEurasia collision and the comparison of short-term and long-term deformation rates, Tectonics, 23, TC2008, doi:10.1029/2003TC001530.

Authemayou, C., D. Chardon, O. Bellier, Z. Malekzadeh, E. Shabanian, M.R. Abbassi, 2006. Late Cenozoic partitioning of oblique plate convergence in the Zagros fold-and-thrust belt (Iran), Tectonics, 25, TC3002, doi:10.1029/2005TC001860.

Berberian, M., and G. C. P. King, 1981. Towards a paleogeography and tectonic evolution of Iran, Can. J. Earth Sci., 18, 210-65.

Bijwaard, H, W. Spakman, and E. R. Engdahl, 1998. Closing the gap between regional and global travel time tomography, J. Geophys. Res., 103, 30055-30078.

Bird, P., M. N. Toksöz, and N. H. Sleep, 1975. Thermal and mechanical models of continentcontinent convergence zones, J. Geophys. Res., 32, 4405-4416.

Bird, P., 1978. Finite element modeling of lithosphere deformation: the Zagros collision orogeny, Tectonophysics, 50, 307-336.

Blanc, E. J. P., M. B. Allen, S. Inger, and H. Hassani, 2003. Structural styles in the Zagros simple folded zone, Iran, J. Struct. Geol., 160, 401-412.

Dehghani, G. A., and J. Makris, 1984. The gravity field and crustal structure of Iran, $N . J b$. Geol. Palaeont. Abh., 168, 215-229.

Giese, P., J. Makris, B. Akashe, P. Röwer, H. Letz, and M. Mostaanpour, 1984. The crustal structure in Southern Iran derived from seismic explosion data, N. Jb. Geol. Palaeont. Abh., 168, 230-243.

Evans, J.R., and U. Achauer, 1993. Teleseismic velocity tomography using the ACH method: theory and application to continental-scale studies, in: Seismic tomography, Theory and practice, H.M. Iyer and K. Irahara (eds), Chapman \& Hall, London, pp. 319-360.

Hafkenscheid, E., M. J. R. Wortel, and W. Spakman (2006), Subduction history of the Tethyan region derived from seismic tomography and tectonic reconstructions, $\mathrm{J}$. Geophys. Res., 111, B08401, doi:10.1029/2005JB003791.

Hatzfeld, D., M. Tatar, K. Priestley, and M. Ghafory-Ashtyany, 2003. Seismological constraints on the crustal structure beneath the Zagros mountain belt (Iran), Geophys. J. Int., 155, 403-410.

Hearn, T.M., and J.F. Ni, 1994. Pn velocities beneath continental collision zones: the TurkishIranian Plateau, Geophys. J. Int., 117, 273-283.

Judenherc, S., 2000. Etude et caractérisation des structures hercyniennes à partir de données sismologiques: le cas du Massif Armoricain, Ph-D thesis, Université Louis Pasteur Strasbourg I, $147 \mathrm{pp}$.

Langston, C. A., 1979. Structure under Mount Rainier, Washington, inferred from teleseismic body waves, J. Geophys. Res., 84(NB9), 4749-4762. 
Ligorria, J. P., and C. J. Ammon, 1999. Iterative deconvolution and receiver-function estimation, Bull. seism. Soc. Am., 89, 1395-1400.

Kaviani, A., A. Paul, E. Bourova, D. Hatzfeld, H. Pedersen, and M. Mokhtari, 2007. A strong seismic velocity contrast in the shallow mantle across the Zagros collision zone (Iran), Geophys. J. Int., 171, 399-410. doi:10.1111/j.1365-246X.2007.03535.x.

Maggi, A., and K. Priestley, 2005. Surface waveform tomography of the Turkish-Iranian plateau, Geophys. J. Int., 160, 1068-1080.

McQuarrie, N, 2004. Crustal-scale geometry of the Zagros fold-thrust belt, Iran, J. Struct. Geol., 26, 519-535.

Molinaro, M., P. Leturmy, J. C. Guezou, and D. Frizon de Lamotte, 2005a. The structure and kinematics of the south-eastern fold-thrust belt, Iran: from thin-skinned to thick-skinned tectonis, Tectonics, 24, TC3007, doi:10.1029/2004TC001633.

Molinaro, M., H. Zeyen, and X. Laurencin, 2005b. Lithospheric structure beneath the southeastern Zagros Mountains, Iran: recent slab break-off? Terra Nova, 17, 1-6.

Mouthereau, F., O. Lacombe, and B. Meyer, 2006. The Zagros Folded Belt (Fars, Iran): Constraints from topography and critical wedge modelling, Geophys. J. Int., 165, 336356.

Mouthereau, F., J. Tensi, N. Bellahsen, O. Lacombe, T. De Boisgrollier, and S. Kargar, 2007. Tertiary sequence of deformation in a thin-skinned/thick-skinned collision belt: The Zagros Folded Belt (Fars, Iran), Tectonics, 26, TC5006, doi:10.1029/2007TC002098.

Omrani J., P. Agard, H. Whitechurch, M. Benoit, G. Prouteau, and L. Jolivet, 2008. Arcmagmatism abd subduction history beneath Zagros: New report of adakites and geodynamic consequences, Lithos, in press.

Paul, A., A. Kaviani, D. Hatzfeld, J. Vergne, and M. Mokhtari, 2006. Seismological evidence for crustal-scale thrusting in the Zagros mountain belt (Iran), Geophys. J. Int., 166, 227237, doi:10.1111/j.1365-246X.2006.02920.x.

Paul A., D. Hatzfeld, A. Kaviani, and M. Tatar, 2008. Lithospheric structure of the Zagros and Alborz mountain belts (Iran) from seismic imaging (abstract), AGU Fall Meeting, San Francisco.

Ricou, L. E., J. Braud, and J. H. Brunn, 1977. Le Zagros, Mém. h. sér. Soc. Géol.. Fr., 8, 3352.

Şengör, A.M.C., S. Özeren, T. Genç, and E. Zor, 2003. East Anatolian high plateau as a mantle-supported, north-south shortened domal structure, Geophys. Res. Lett., 30 (24), 8045, doi:10/129/2003GL017858.

Sherkati, S, and J. Letouzey, 2004. Variation of structural style and basin evolution in the central Zagros (Izeh zone and Dezful Embayment), Iran, Marine and Petroleum Geology, 21, 535-554.

Snyder D. B., and M. Barazangi, 1986. Deep crustal structure and flexure of the Arabian plate beneath the Zagros collisional mountain belt as inferred from gravity observations, Tectonics, 5, 361-373.

Stöcklin, J., 1968. Structural history and tectonics of Iran: A review, American Association of Petroleum Geologists Bulletin, 52, 1229-1258.

Talebian, M., and J. Jackson, 2004. A reappraisal of earthquake focal mechanisms and active shortening in the Zagros mountains of Iran, Geophys. J. Int., 156, 506-526.

Tchalenko, J.S., and J. Braud, 1974. Seismicity and structure of the Zagros (Iran): the Main Recent Fault between 33 and $35^{\circ}$ N, Phil. Trans. Roy. Soc. Lond., 277, 1-25.

Vernant, P., F. Nilforoushan, D. Hatzfeld, M. R Abassi, C. Vigny, F. Masson, H. Nankali, J. Martinod, A. Ashtiani, R. Bayer, F. Tavakoli, and J. Chéry, 2004. Present-day crustal deformation and plate kinematics in the Middle East constrained by GPS measurements in Iran and northern Oman, Geophys. J. Int., 157, 381-398. 
Vinnik, L. P., 1977. Detection of waves converted from P to SV in the mantle, Phys. Earth Planet. Inter., 15, 39-45.

Walpersdorf, A., D. Hatzfeld, H. Nankali, F. Tavakoli, F. Nilforoushan, M. Tatar, P. Vernant, J. Chéry, and F. Masson, 2006. Difference in GPS deformation pattern of North and Central Zagros (Iran), Geophys. J. Int., 167, 1077-1088.

Zhu, L. P., and H. Kanamori, 2000. Moho depth variation in southern California from teleseismic receiver functions, J. Geophys. Res., 105, 2969-2980. 


\section{Figure and table captions}

Figure 1. Location map of the seismic experiments. Temporary seismic stations are shown as black-filled circles. The dash-and-dot black lines are the average profiles used to compute the depth cross-sections of Figures 2 to 6 . Geological map modified from the structural map of NGDIR (National Geoscience Database of Iran, http://www.ngdir.ir). MZRF: Main Zagros Reverse Fault; KF: Kazerun Fault; ZFTB: Zagros fold-and-thrust belt; SSZ: Sanandaj-Sirjan Zone; UDMA: Urumieh-Dokhtar Magmatic Assemblage; CD: Central Domain; AL: Alborz

Figure 2. Depth-sections of radial receiver function records of the Central Zagros profile (Zagros01) plotted along the average profile shown in Fig. 1. Distance is measured with respect to the intersection of the profile with the surface exposure of the MZRF. a) Topography profile and locations of seismic stations (black triangles). b) Commonconversion point depth migrated cross-section (from Paul et al. 2006). c) Radial receiver function records stacked for a common location of the piercing point of the ray at the Moho. Time-to-depth conversion uses the velocity models of Table 1 . The solid black line is the Moho depth profile picked from Fig. 2b. The dashed line is the crustal-scale thrust hypothesized by Paul et al. (2006) to fit RF and gravity data. Same abbreviations as in Fig. 1.

Figure 3. Same as Figure 2 for the Northern Zagros profile (Zagros03). The dashed line underlines the crustal interface with negative velocity contrast (velocity decreasing with increasing depth) interpreted as the trace of the MZRF.

Figure 4. Comparison of (a) the topography profiles, (b) the Bouguer anomaly data, and (c) the Moho depth profiles picked from receiver functions for the Central Zagros (blue) and Northern Zagros (red) experiments. The distance scale of the Northern Zagros profile was multiplied by 0.94 to correct for the slightly wider SSZ along this transect. The dotted line shows the location of the MZRF.

Figure 5. $P$-wave tomography and local $S$-wave velocity models for the Central Zagros profile (Zagros01). (a) Topography profile and locations of seismic stations. The three vertical lines show the boundaries of the main morphotectonic units. (b) $P$-traveltime relative 
residuals plotted for each station at the abscissa of the projection of the station onto the average profile. (c) Depth cross-section along the average profile in the 3-D model of $P$ wave velocity perturbations resulting from the inversion of residuals. The black solid line is the Moho depth profile picked from the receiver function data. The vertical dotted lines bound the areas covered by surface wave dispersion measurements in sub-arrays AB (ZFTB) and BCD (MZRF-SSZ-UDMA region). (d) Mantle $S$-wave velocity depth models resulting from the inversion of surface wave dispersion curves measured in sub-arrays $A B$ (left panel) and BCD (right panel).

Figure 6. $P$-wave traveltime residuals (b) and depth profile of lateral $P$-wave velocity variations (c) for the Northern Zagros profile (Zagros03).

Figure 7. Schematic model proposed for the evolution of the lithospheric structure of the Zagros from the onset of continental collision (a) to present time (b). The present-day structural model is based on the Moho depth profile and the trace of the MZRF picked from the receiver function migrated depth section of the Northern Zagros transect (Fig. 3).The surface of the crustal root filled in grey is used to estimate shortening. The mantle structure is interpreted from the $P$-wave tomography of Fig. 6 c. No vertical exaggeration. 


\begin{tabular}{|c|c|c|c|c|c|c|c|c|c|c|c|}
\hline \multicolumn{6}{|c|}{ ZFTB $(x \leq 0 \mathrm{~km})$} & \multicolumn{6}{|c|}{ SSZ-UDMA-CD-Alborz $(x>0 \mathrm{~km})$} \\
\hline \multicolumn{3}{|c|}{ Zagros01 } & \multicolumn{3}{|c|}{ Zagros03-Alborz03 } & \multicolumn{3}{|c|}{ Zagros01 } & \multicolumn{3}{|c|}{ Zagros03-Alborz03 } \\
\hline $\begin{array}{c}\mathrm{H} \\
(\mathrm{km})\end{array}$ & $\begin{array}{c}V p \\
(\mathrm{~km} / \mathrm{s})\end{array}$ & $\mathrm{Vp} / \mathrm{Vs}$ & $\begin{array}{c}\mathrm{H} \\
(\mathrm{km})\end{array}$ & $\begin{array}{c}V p \\
(\mathrm{~km} / \mathrm{s})\end{array}$ & $\mathrm{Vp} / \mathrm{Vs}$ & $\begin{array}{c}\mathrm{H} \\
(\mathrm{km})\end{array}$ & $\begin{array}{c}\mathrm{Vp} \\
(\mathrm{km} / \mathrm{s})\end{array}$ & $\mathrm{Vp} / \mathrm{Vs}$ & $\begin{array}{c}\mathrm{H} \\
(\mathrm{km})\end{array}$ & $\begin{array}{c}\mathrm{Vp} \\
(\mathrm{km} / \mathrm{s})\end{array}$ & $\mathrm{Vp} / \mathrm{Vs}$ \\
\hline 11 & 4.7 & 1.77 & 11 & 4.7 & 1.8 & 20 & 5.8 & 1.73 & 20 & 5.8 & 1.8 \\
\hline 9 & 5.8 & 1.73 & 9 & 5.8 & 1.8 & 25 & 6.5 & 1.73 & 25 & 6.5 & 1.8 \\
\hline 25 & 6.5 & 1.73 & 25 & 6.5 & 1.8 & & & & & & \\
\hline
\end{tabular}

Table 1. Crustal velocity models used in the depth migration of the receiver functions. $\mathrm{H}$ is the layer thickness. 


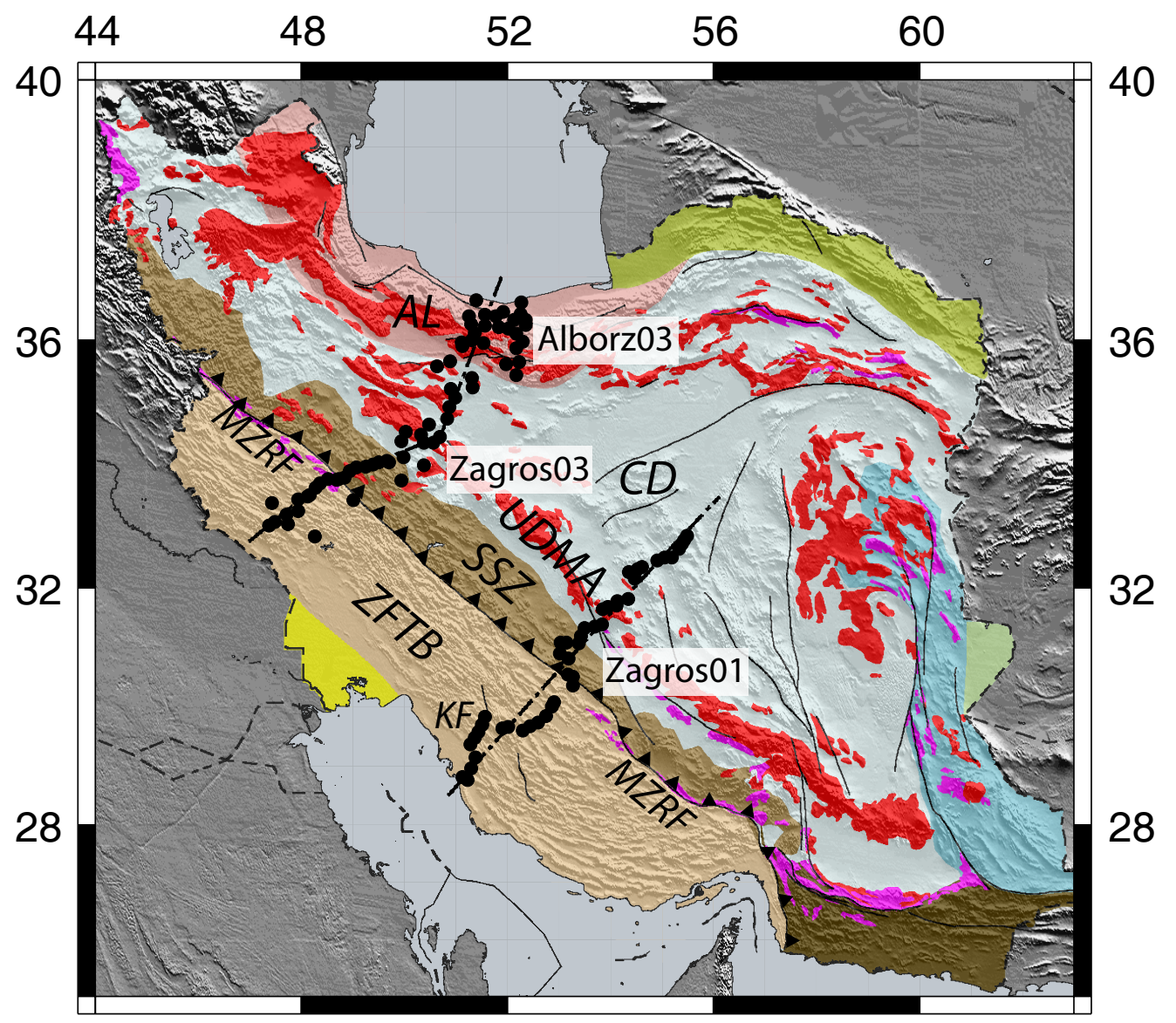

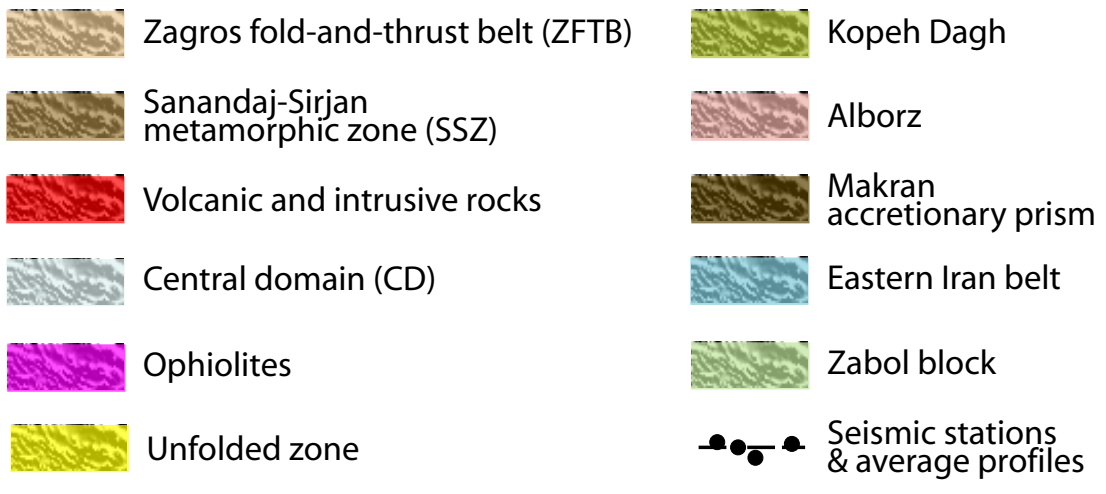

Figure 1 


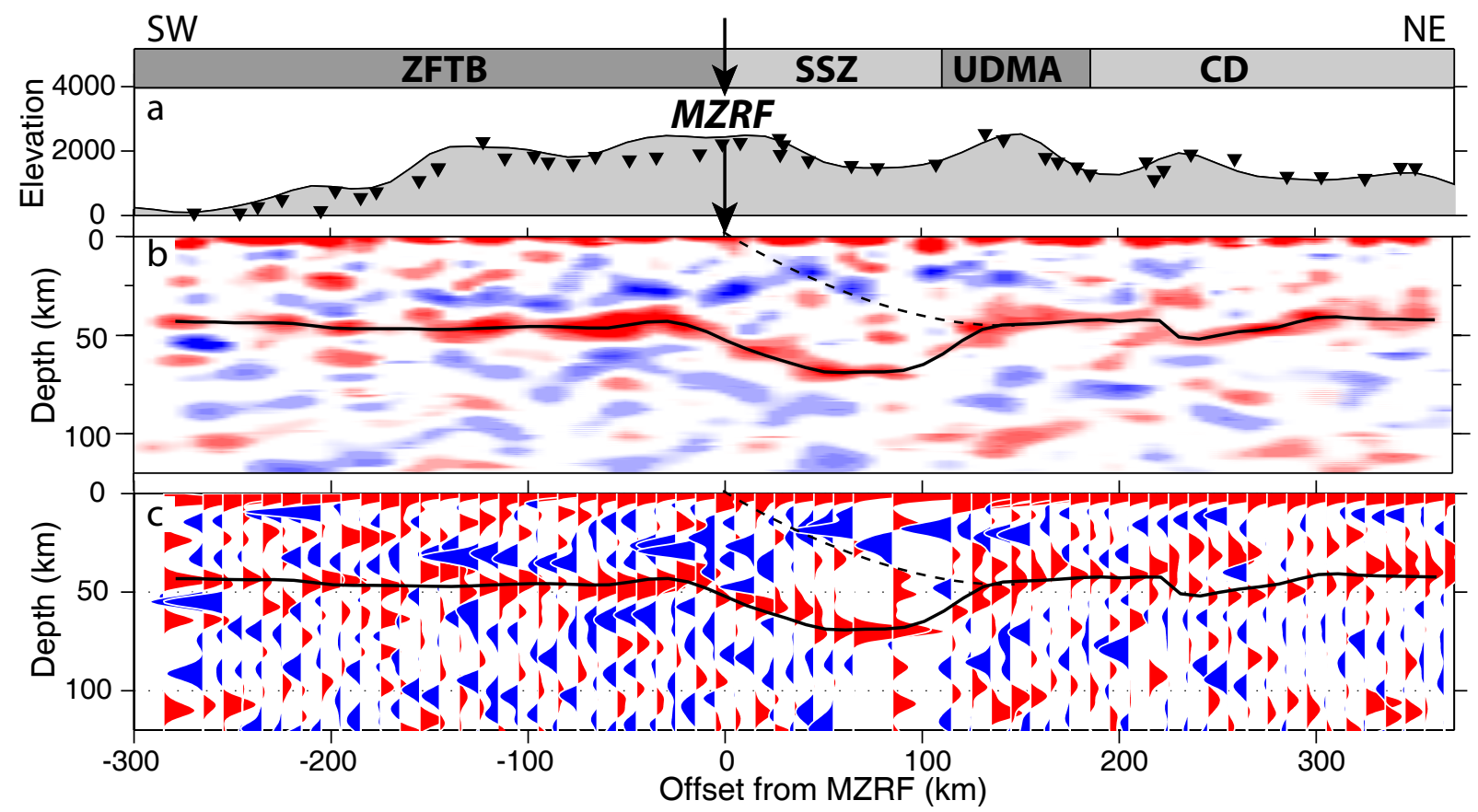

Figure 2 

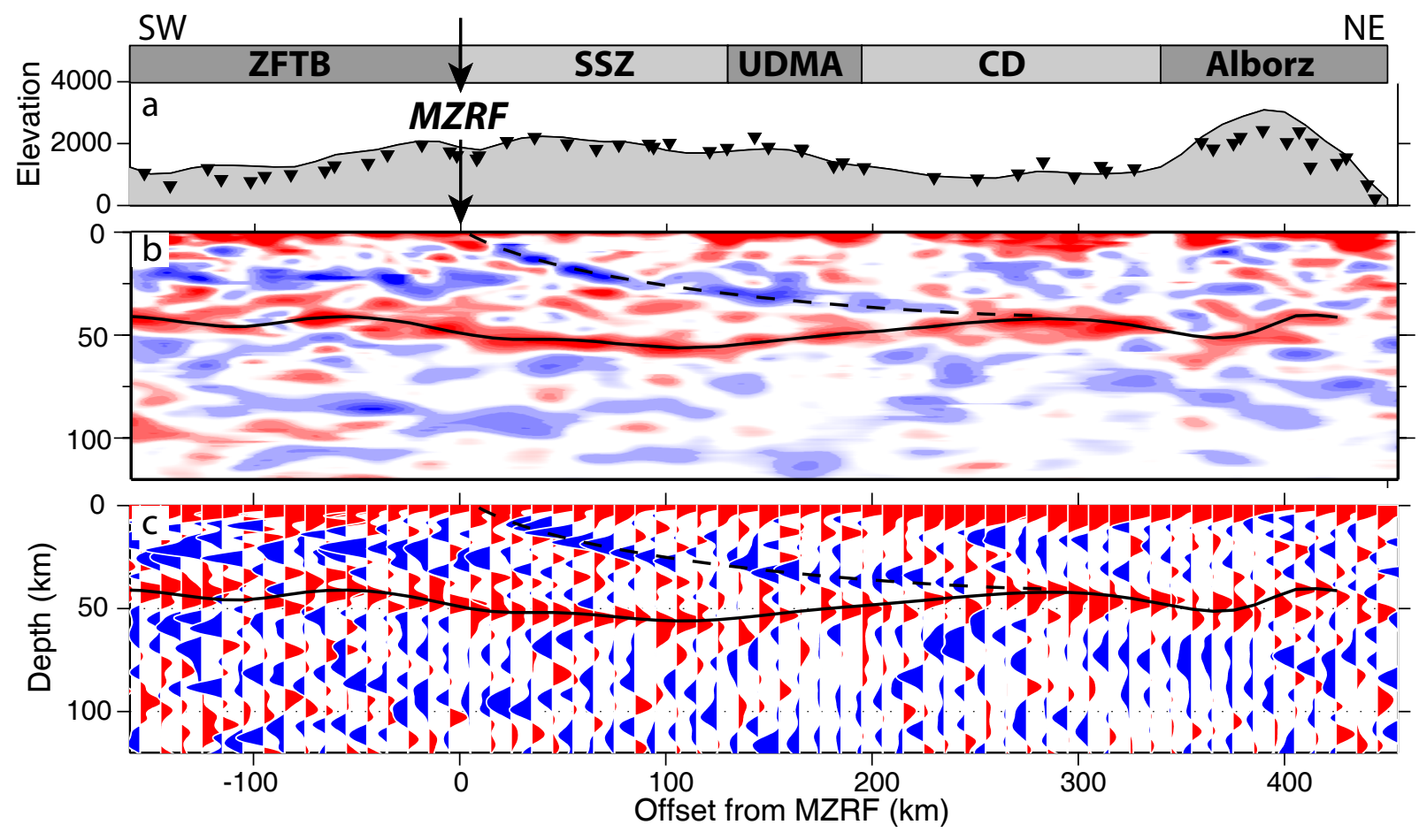

Figure 3 


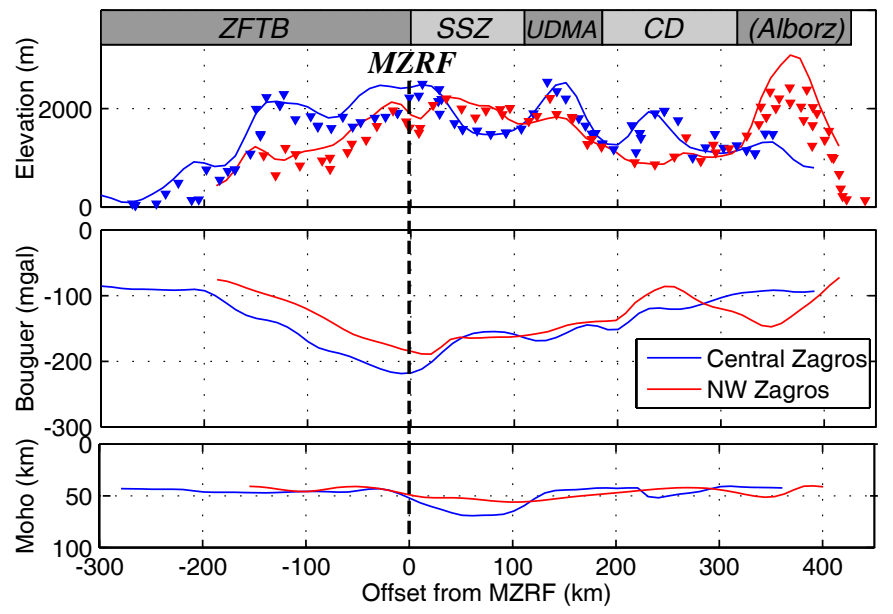

Figure 4 


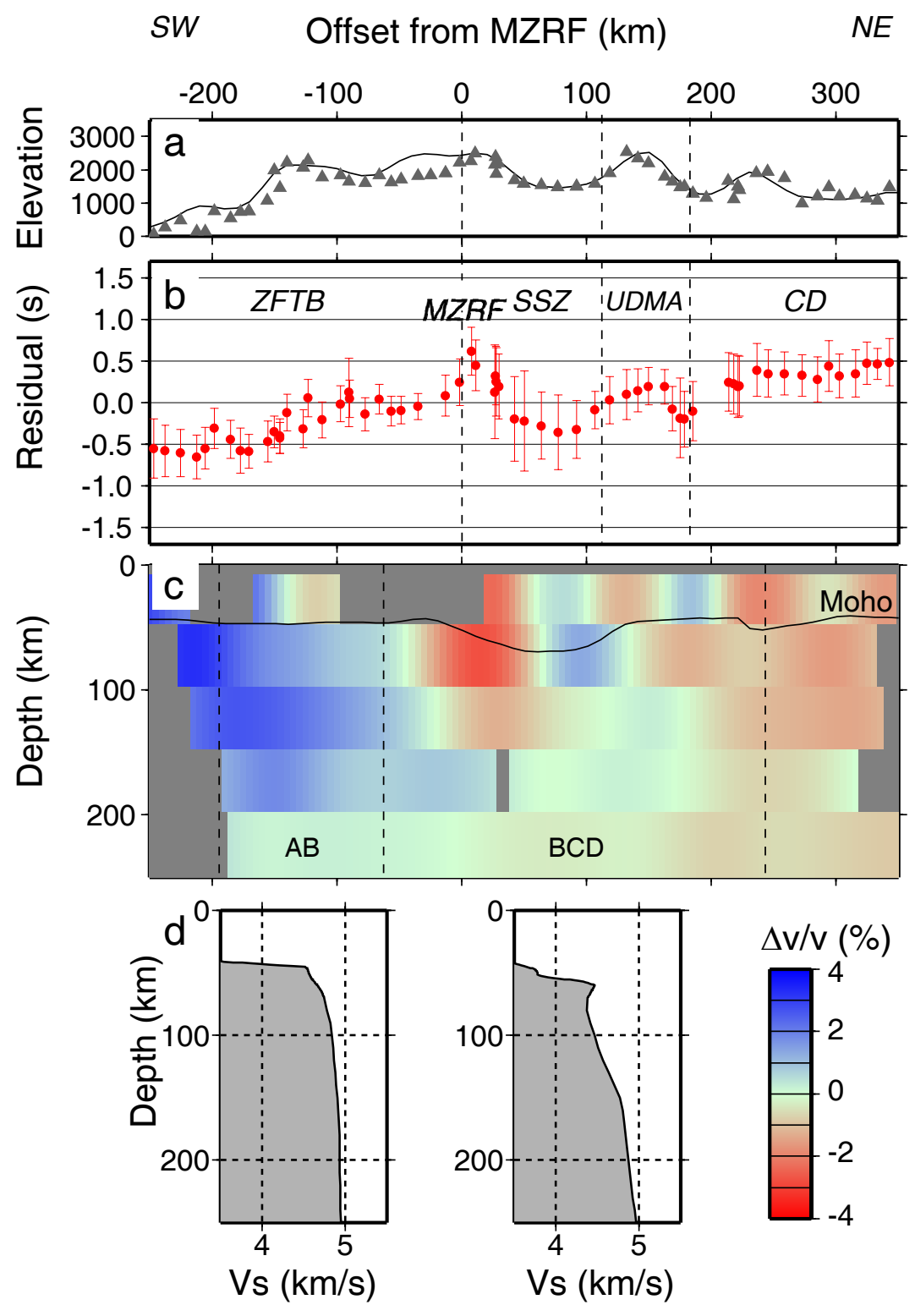

Figure 5 


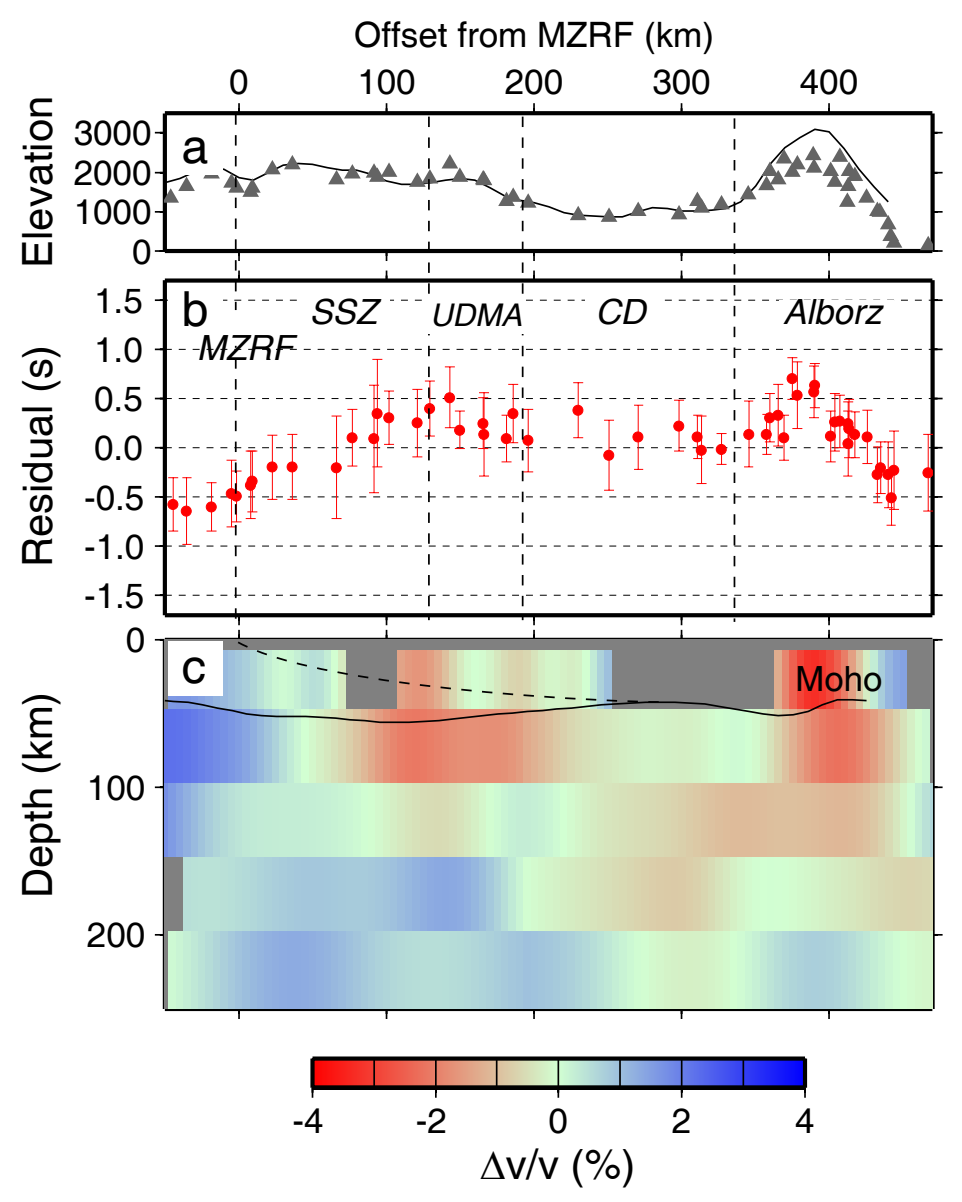

Figure 6 
a. End of oceanic subduction, transition to continental collision

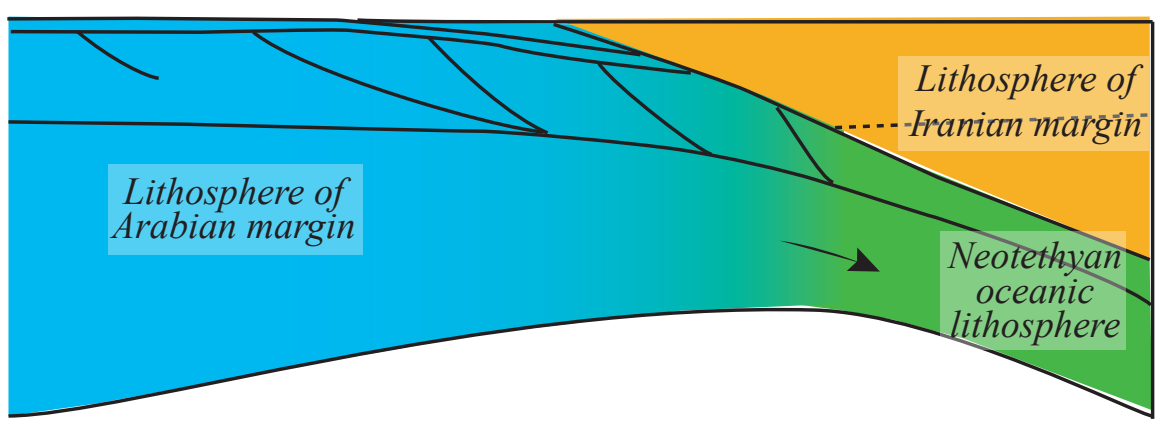

$100 \mathrm{~km}$

b. Present-day structure

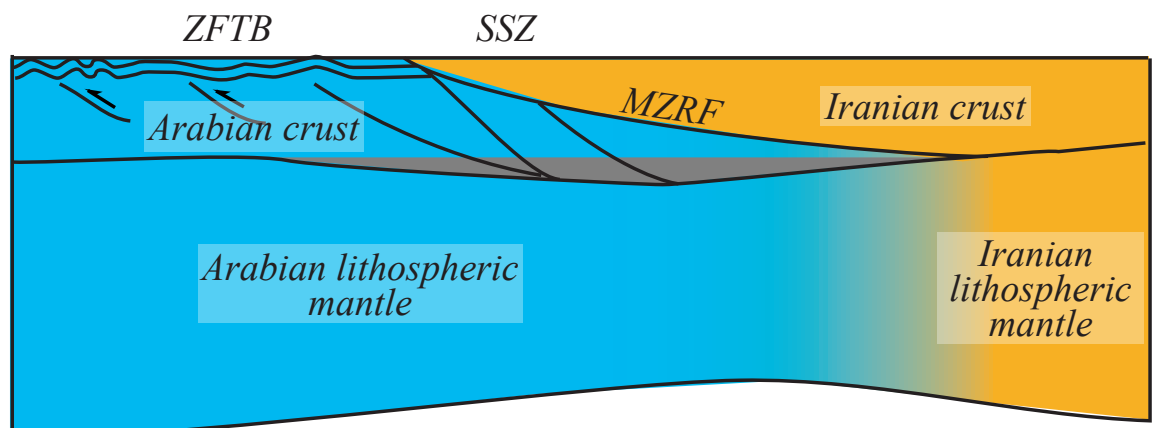

Figure 7 